\title{
INDEX OF PAPERS PUBLISHED IN THIS VOLUME ARRANGED ACCORDING TO NAMES OF AUTHORS
}

[The numbers refer to pages.]

Aitken, A. C. .

Bosanquet, L. S. Campbell, J. 'T. Cannon, E. W., and Wintner, A

Edge, W. I

Gillespie, R. P. Gupta, Hansraj

Haslam-Jones, U. S. Humbert, P. Hyslop, J. M.

Ledermann, W.

Littlewood, D. E. Macintyre, A. J.

Mehrotra, B. M.

Mitra, S. C.

Motzkin, Th.

Peddie, W.

Richmond, H. W.

Ruse, H. S.

Saddler, W.

Scott, T. .

Shabde, N. G.

Note on a selection from a multivariate normal population, 106.

Obituary notice of Sir Thomas Muir, 263.

The absolute summability $(A)$ of Fourier series, 12.

The Poisson correlation function, 18.

An asymptotic formula for a class of distribution functions, 138.

The problem of the in-and-circumscribed polygon for a plane quartic curve, 121.

A special net of quadrics, 185.

On a simple type of integro-differential equation, 80.

Congruence properties of $G$-functions, 61 .

On a theorem of Gauss, 118.

Obituary notice of Professor B. M. Wilson, 268.

Some new operational representations, 232.

On the summability of series by a method of Valiron, 218.

Reduction of singular pencils of matrices, 92.

A theorem on alternants, 262.

An elementary proof of the theorems of Cauchy and Mayer, 112.

Theorems connecting different classes of self-reciprocal functions, 53 .

- On the squares of Weber's parabolic-cylinder functions and certain integrals connected with them, 27.

The operational representations of $D_{n}(x)$ and $\left(D_{-(n+1)}^{\mathrm{g}}(i x)\right.$ $\left.-D_{-(n+1)}^{2}(-i x)\right), 33$.

On certain new connections between Legendre and Bessel functions, 111.

On vanishing coaxial minors, 210.

Obituary notice of Professor J. E. A. Steggall, 270.

On the tritangent planes of a quadri-cubic space-curve, 159.

Gauss' theorem in a general space-time, 144.

On certain equations to the cubic surface, with extensions to higher space, 1.

A geometrical interpretation of the symmetrical invariant of three ternary quadratics, 258.

On some definite integrals involving Legendre functions, 41.

Sokolnikoff, I. S. and E.S. Note on a resolution of linear differential systems, 36.

Todd, J. A. . . . On the topology of certain algebraic threefold loci, 175. 
Turnbull, H. W. - . Obituary notice of Professor D. M. Y. Sommerville, 57. On the reduction of singular matrix pencils, 67.

Walker, A. G. . . . Note on relativistic mechanics, 370.

The Boltzmann equations in general relativity, 238.

Walsh, C. E. . . . An addendum, 79.

Weatherburn, C. E. . . On certain quadric hypersurfaces in Riemannian space, 85.

Whittaker, E. T. . . Obituary notice of Dr E. M. Horsburgh, 272.

Whittaker, J. M. . . Note on the "sum" of an integral function, 77.

The asymptotic periods of integral and meromorphic functions, 254.

Williamson, J. . . . . On the equivalence of two singular matrix pencils, 224.

Zia-ud-Din, M. . . On determinantal symmetric functions, 47 .

\title{
INDEX ACCORDING TO SUBJECTS
}

\author{
[The numbers refer to pages.] \\ Algebra . . . . Ledermann, W., 92: Littlewood, D. E., 262 : Motzkin, \\ Th., 210 : Turnbull, H. W., 67: Williamson, J., 224: \\ Zia-ud-Din, M., 47.
}

Differential Equations Macintyre, J., 112.

Functions, Theory of $\quad$. Cannon, E. W., and Wintner, A., 138: Mehrohtra, B. M., 53: Mitra, S. C., 27, 33, 111: Shabde, N. G., 41: Sokolnikoff, I. S. and E. S., 36: Whittaker, J. M., $77,254$.

Geometry, Algebraic . . Edge, W. L., 121, 185: Richmond, H. W., 159: Saddler, W., 1: Scott, T., 258.

Geometry, Riemannian . Weatherburn, C. E., 85.

Numbers, Theory of . . Gupta, H., 61., 118.

Obituaries . . . Aitken, A. C., 263: Haslam-Jones, U. S., 268: Peddie, W., 270 : Turnbull, H. W., 57 : Whittaker, E. T., 272.

Operational Calculus . Humbert, P., 232 : Mitra, S. C., 33.

Relativity. . . . Ruse, H. S., 144 : Walker, A. G., 170., 238.

Series, Infinite . . Bosanquet, L. S., 12: Hyslop. J. M., 218 : Walsh, C. E., 79 .

Statistics . . . $\quad \cdot$ Aitken, A. C., 106 : Campbell, J. T., 18: Cannon, E. W., and Wintner, A., 138.

Topology . . . . . Todd, J. A., 175.

Variations, Calculus of . Gillespie, R. P., 80. 